\title{
Efficacy of oncolytic reovirus against human gastric cancer with peritoneal metastasis in experimental animal model
}

\author{
KOJI KAWAGUCHI ${ }^{1}$, TSUYOSHI ETOH ${ }^{1}$, KOSUKE SUZUKI ${ }^{1}$, MARCELO TAKAHIRO MITUI ${ }^{2}$, \\ AKIRA NISHIZONO $^{2}$, NORIO SHIRAISHI ${ }^{1}$ and SEIGO KITANO ${ }^{1}$ \\ ${ }^{1}$ Departments of Surgery I and ${ }^{2}$ Microbiology, Oita University Faculty of Medicine, Oita, Japan
}

Received June 28, 2010; Accepted August 6, 2010

DOI: 10.3892/ijo_00000795

\begin{abstract}
The prognosis of gastric cancer patients with peritoneal dissemination is extremely poor, and the development of an effective treatment is necessary. The aim of this study was to investigate the efficacy of oncolytic reovirus against peritoneal metastasis in human gastric cancer using an experimental animal model. Four human gastric cancer cell lines, including MKN45p, NUGC4, MKN7 and KatoIII, a normal NIH3T3 cell line as a control, and reovirus serotype 3, were used in this study. We evaluated the cytopathic effect of reovirus and the Ras activity in each gastric cancer cell line in vitro. To evaluate oncolytic efficacy in vivo, reovirus $\left(1 \times 10^{8} \mathrm{PFU}\right)$ was administered into the peritoneal cavity of nude mice on days 7, 8 and 9 after inoculation with MKN45p cells. Mean volume of ascites and the total number and weight of the peritoneal tumors were measured after sacrifice. After reovirus infection, cytopathic effect was observed in all four gastric cancer cell lines, but not in the control cells. Ras activation assay showed that Ras activity in all four gastric cancer cell lines increased to a higher level than that in the control cells. In the animal model experiments, mean volume of ascites and the total number and weight of the peritoneal tumors in the reovirus treatment group were significantly lower than those in the control group. In conclusions, intraperitoneal administration of reovirus could be useful as a new modality against peritoneal metastasis in gastric cancer.
\end{abstract}

\section{Introduction}

Gastric cancer is one of the most common cancers in Japan, and its incidence is six to eight times greater in many Asian and Eastern European countries than it is in the West (1). Prognosis in patients with early-stage cancer is favorable after surgical resection. However, the survival rate of patients with advanced gastric cancer remains poor because they

Correspondence to: Dr K. Kawaguchi, Department of Surgery I, Oita University Faculty of Medicine, 1-1 Idaigaoka, Yufu, Oita 879-5593, Japan

E-mail:kojik@oita-u.ac.jp

Key words: reovirus, peritoneal metastasis, gastric cancer experience frequent peritoneal, lymph node and liver metastasis with this disease. Median survival time for patients with peritoneal dissemination after surgery is reported to be $\sim 10$ months (2). Therefore, various new treatments have been developed for gastric cancer with peritoneal dissemination, including systemic chemotherapy, intraperitoneal chemotherapy and/or hyperthermia, and surgery with extended dissection of lymph nodes or other organs (3-7). To date, however, the results of these therapies have been unsatisfactory. It is thus necessary to develop an effective modality to treat gastric cancer with peritoneal dissemination.

Human reovirus is a unique oncolytic, non-enveloped virus containing 10 segments of double-stranded RNA as its genome. Reovirus is a common isolate of the respiratory and gastrointestinal tract of humans, but it is not associated with any known human diseases. Reovirus requires an activated Ras signaling pathway via direct Ras mutation or downstream of independent pathways of Ras such as epidermal growth factor receptor, Her-2(Neu/ErbB-2), or SOS in infected cultured cells (8). Activated Ras or an activated element of the Ras pathway inhibits the actination of double-stranded RNA-activated protein kinase, thus allowing both viral protein synthesis and lytic infection to occur. The oncolytic efficacy of reovirus has been shown in several cancer models in vivo such as those for pancreatic cancers, malignant glioma, colon, ovarian and breast cancers, and lymphoid malignancy (9-14).

The aim of this study was to investigate the antitumor effect of intraperitoneal administration of reovirus against peritoneal metastasis from gastric cancer in an experimental animal model. To our knowledge, this is the first study to investigate the use of reovirus as an anticancer agent for gastric cancer.

\section{Materials and methods}

Cell lines and virus. Four human gastric cancer cell lines including MKN45p, NUGC4, MKN7 and KatoIII, and a normal NIH3T3 cell line as control were provided from the RIKEN cell bank (Ibaragi, Japan) and were used in this study. These four cancer cell lines were cultured in RPMI-1640 medium containing 10\% FBS and antibiotics. The NIH3T3 cell line was cultured in DMEM containing 10\% FBS and antibiotics. Reovirus serotype 3 was kindly provided by Dr K. Hirasawa (University of Calgary, Calgary, Canada). 
Reovirus serotype 3 Dearing (ReoT3D) was purified according to the protocol of Smith et al with the exception that 2-mercaptoethanol was omitted from the extraction buffer (15). For reovirus collection, L929 cells grown in $175-\mathrm{cm}^{2}$ flasks were infected with reovirus at a MOI of 1 . After $48 \mathrm{~h}$ of incubation, cells and supernatants were frozen and thawed three times. Viral titer was determined by plaque assays using L929 cells, and the virus was purified and stored at $-80^{\circ} \mathrm{C}$ as described previously (16).

Cytotoxicity in cell lines. We evaluated the effect of reovirus on gastric cancer cell lives in vitro. For evaluation of susceptibility to reovirus in vitro, each cell line was plated onto 12 -well dishes at $1 \times 10^{5}$ cells/well and was infected with reovirus at a MOI 10 and maintained in RPMI-1640 with $10 \%$ FBS at $37^{\circ} \mathrm{C}$. On days $1,3,5$ and 7 after reovirus infection, we observed a cytopathic effect (CPE) and counted the number of viable cells with a hemocytometer using the trypan blue exclusion method.

Measuring Ras activity. Ras activity in gastric cancer cells was examined with a Ras activation ELISA assay kit (Upstate Biotechnology, Charlottesville, VA, USA). Briefly, this kit is designed to detect the presence of activated Ras and can be used to study novel Ras activating pathways. The Ras binding domain (RBD) of Raf-1 kinase is a downstream target of activated Ras-GTP. Raf-1-RBD serves to capture any available active Ras-GTP within samples that are added to the wells. Ras proteins captured by the Raf-1-RBD are detected and measured quantitatively through the addition of a mouse monoclonal anti-Ras antibody that detects the Ras isoforms N, H, K from mouse species. An HRP-conjugated secondary antibody against mouse is then added. Following addition of the chemiluminescent substrate, signals can be measured using a luminometer or with a CCD camera.

Intraperitoneal tumor xenograft model in nude mice. Sixweek-old male athymic BALB/c nude mice, purchased from Kyushu Animal Co., (Kumamoto, Japan) were kept under pathogen-free conditions according to the Animal Center guidelines for our facilities. MKN45p cells $\left(5 \times 10^{6}\right)$ suspended in $400 \mu 1$ of PBS were injected into the peritoneal cavity of the anesthetized mice. The mice were randomly divided into two groups, the control and treatment group (10 mice/group). Reovirus $\left(1 \times 10^{8} \mathrm{PFU}\right)$ in $400 \mu \mathrm{l}$ of PBS was administered into the peritoneal cavity of the nude mice under general anesthesia on days 7,8 and 9 after inoculation with MKN45p cells. An equivalent amount of PBS without reovirus was administered in the control group. The condition of each mouse was checked twice daily during this study. All animals were sacrificed on day 18 after inoculation with the MKN45p cells. Following this, we counted the numbers of the metastatic nodules in the peritoneal cavity and measured the volume of ascites in the peritoneal cavity of the mice. The metastatic nodules found in the peritoneal cavity were fixed in $10 \%$ neutral-buffered formaldehyde, embedded in paraffin, and sectioned. The specimens were then stained with H\&E stain.

Reverse transcriptase-polymerase chain reaction ( $R T-P C R)$ analysis for detection of reovirus. To evaluate the presence of genomic dsRNA of the reovirus in vitro and in vivo, reverse transcription and polymerase chain reactions were performed in an iCycler Thermal Cycler (Bio-Rad Laboratories, USA). Reverse transcription and the PCR reaction were carried out with specific forward and reverse primers. A segment of the reovirus subgenomic sequence from the L1 gene that partially encodes the minor core protein lambda 3 was amplified.

The primers for the primary L1 gene RT-PCR assay L1.rv5 (forward: 5'-GCATCCATTGTAAATGACGAGT CTG-3') and L1.rv6 (reverse: 5'-CTTGAGATTAGCTCTA GCATCTTCTG-3'), which form a 416-bp RT-PCR product, were targeted. An aliquot of $3 \mu 1$ of dsRNA was heated to $97^{\circ} \mathrm{C}$ for $5 \mathrm{~min}$ and was then immediately placed on ice for denaturation. Following the manufacturer's recommendations, one-step RT-PCR reactions (total of $50 \mu \mathrm{l}$ ) were performed with the Access Quick RT-PCR system (Promega Corporation, Madison, WI, USA), and each contained $25 \mu 1$ MasterMix, $1 \mu 1$ reverse transcriptase enzyme (AMV), $0.2 \mu \mathrm{M}$ of each specific primer, and $2 \mu 1$ of dsRNA and RNase-free water up to $50 \mu 1$.

The RT-PCR reactions were initially reverse transcribed at $45^{\circ} \mathrm{C}$ for $45 \mathrm{~min}$, denatured at $94^{\circ} \mathrm{C}$ for $1 \mathrm{~min}$, and then cycled 35 times under the following conditions: $94^{\circ} \mathrm{C}$ for $20 \mathrm{sec}, 50^{\circ} \mathrm{C}$ for $30 \mathrm{sec}$, and $72^{\circ} \mathrm{C}$ for $30 \mathrm{sec}$, and with one final terminal annealing step of $7^{\circ} \mathrm{C}$ for $3.5 \mathrm{~min}$. Electrophoresis of each PCR product was performed in $2 \%$ agarose gel, and following ethidium bromide staining, the results were viewed under the GelDoc XR image-analysis system (BioRad Laboratories, USA).

Statistical analysis. All values are expressed as the mean \pm SD. Statistical differences among groups were assessed with Student's t-test. $\mathrm{P}<0.05$ was considered to be significant.

\section{Results}

In vitro cytopathic efficacy. To evaluate susceptibility to the reovirus, the four gastric cancer cell lines were infected at a MOI of 10 viral particles/cell. All four gastric cancer cell lines were efficiently destroyed by reovirus within 1 week. A CPE appeared from day 1 after infection, and 50\% or greater cytotoxicity was shown at day 7 after infection, as shown in Fig. 1A. In contrast, the NIH3T3 control cells were resistant to reovirus infection. In addition, severe morphological changes were also seen in all four cancer cell lines infected (Fig. 1B).

Detection of Ras activities in gastric cancer cell lines. The amount of Ras-GTP was measured with the Ras activation ELISA kit. Ras activation assay showed that Ras activity was increased in all four gastric cancer cell lines and, interestingly, was especially high in MKN45p cells, whereas the measured quantity was low in the control cells, as expected (Fig. 2).

RT-PCR in gastric cancer cell lines. RT-PCR was performed for detection of reovirus. The amplified genomic segment of reovirus in reovirus-infected gastric cancer cells is shown in Fig. 3. The reovirus L1 gene segment region was detected in all four cancer cell lines. However, the reovirus L1 gene segment region was not detected in the control cells. 
A

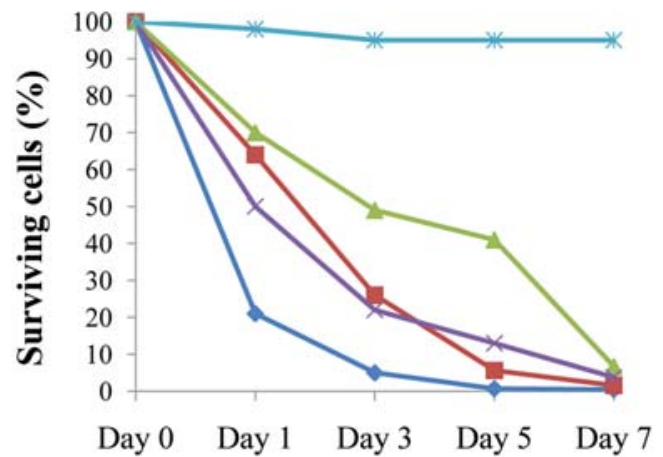

Days postinjection
B

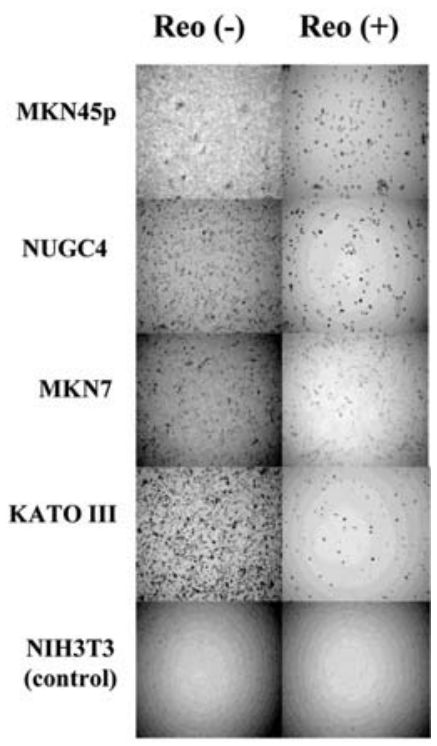

$(+)$ : Reovirus treatment (-): Reovirus control

Figure 1. Effect of reovirus on human gastric cancer cell lines MKN45p, NUGC4, MKN7 and KatoIII, and a normal NIH3T3 cell line. (A) Cytopathic effect of reovirus in gastric cancer cell lines. (B) Morphological changes after reovirus infection. Morphological changes were seen in infected cancer cell lines after $48 \mathrm{~h}$ of infection.

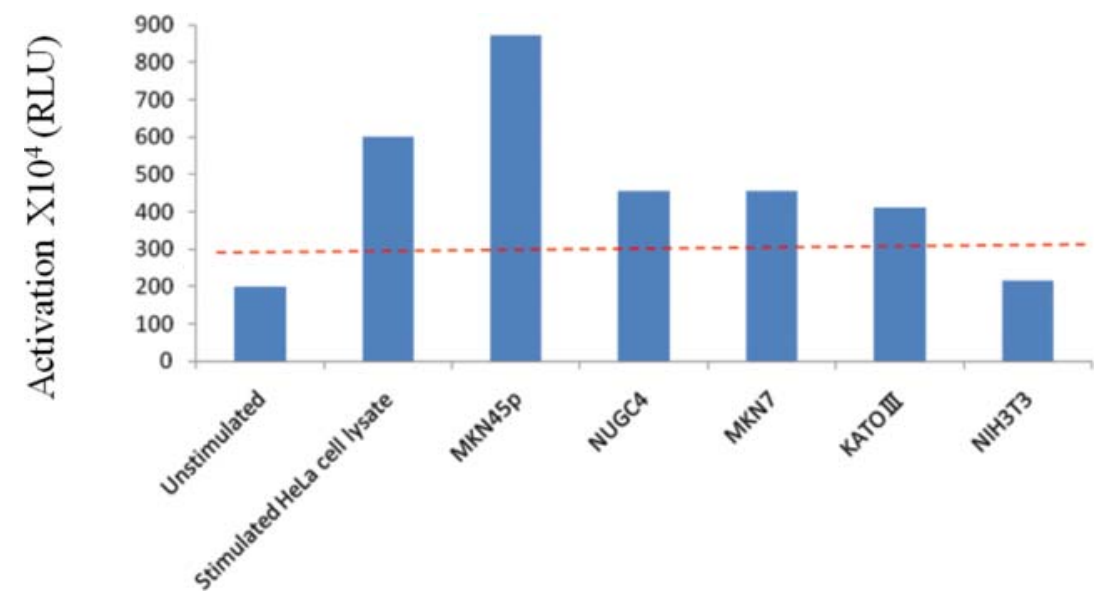

Figure 2. Detection of Ras activity in gastric cancer cell lines. Ras activation assay showed that Ras activity in all four gastric cancer cell lines was increased above that in the NIH3T3 control cells and was especially high in the MKN45p cells. RLU, relative light units.

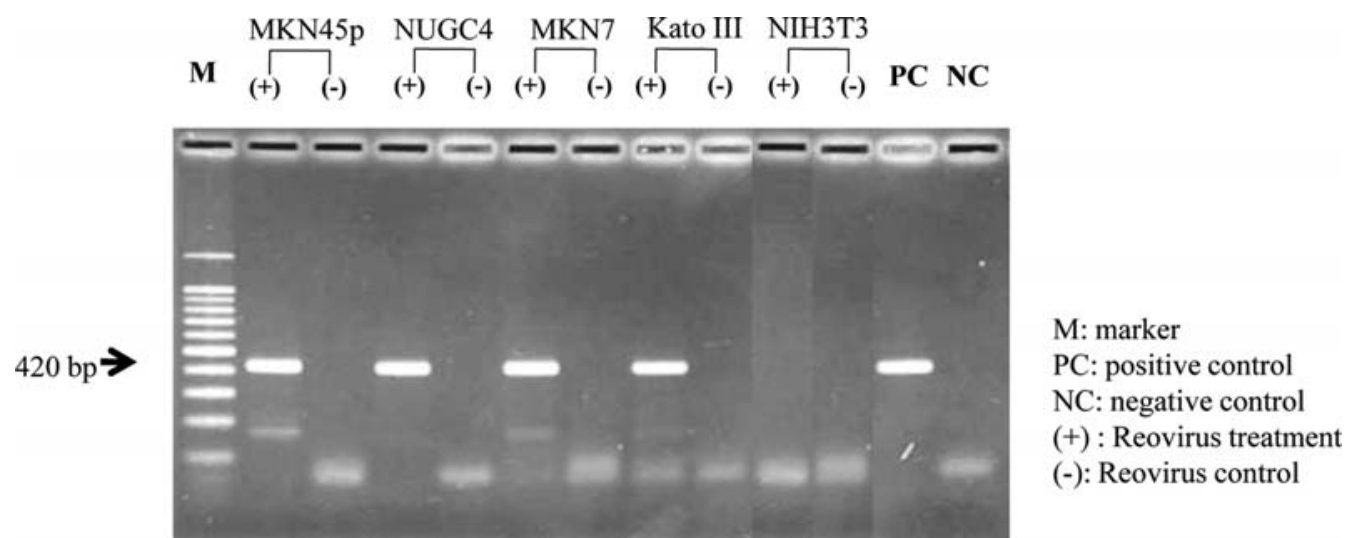

Figure 3. RT-PCR detection of reovirus. The reovirus L1 gene segment region was detected in all four cancer cell lines but not in the NIH3T3 control cell line. 
A

Reovirus control

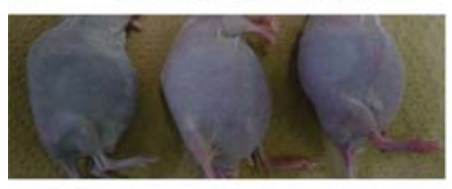

$\mathrm{C}$

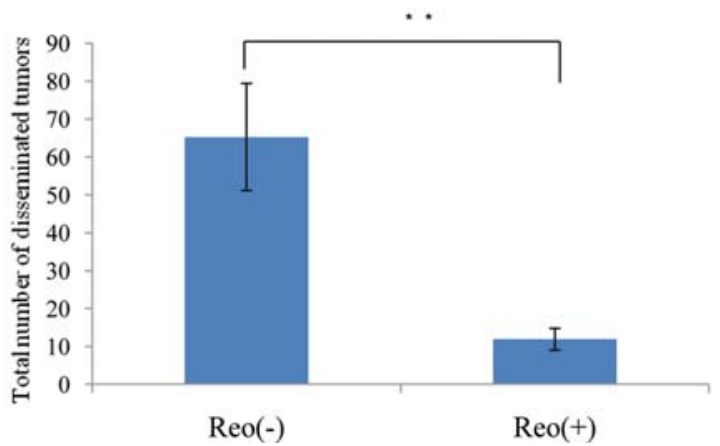

$\mathrm{B}$

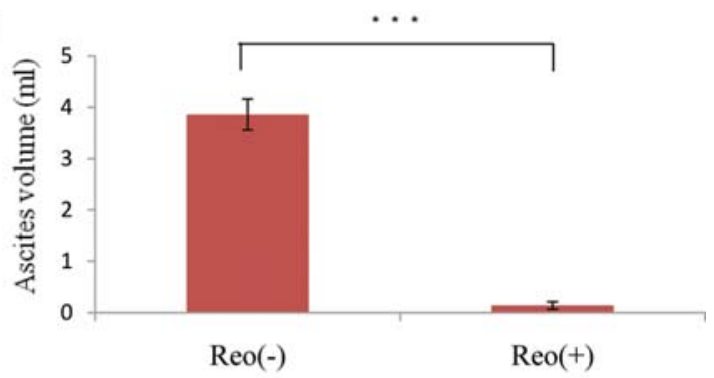

D

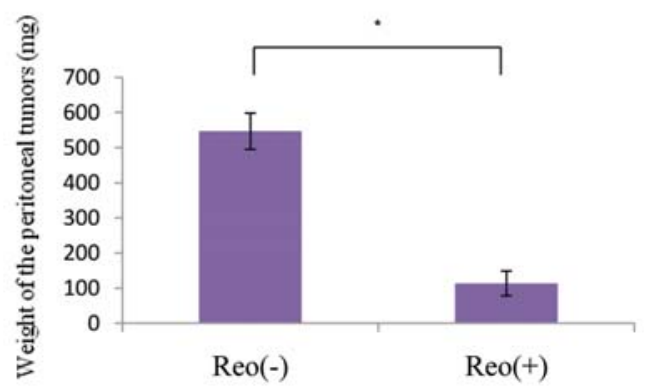

Figure 4. The effect of intraperitoneal injections of reovirus. (A) An image of representative mice on day 18 after MKN45p inoculation. (B) Mean volume of ascites in the treated and untreated mice. (C) Mean total number of disseminated tumors in the mesenteri of treated and untreated mice. (D) The total weight of the peritoneal tumors in the mesenteri of treated and untreated mice. The differences were statistically significant $\left({ }^{* * *} \mathrm{p}<0.05,{ }^{* *} \mathrm{p}<0.05,{ }^{*} \mathrm{p}<0.05\right)$. Data represent the mean $\pm \mathrm{SD}$.

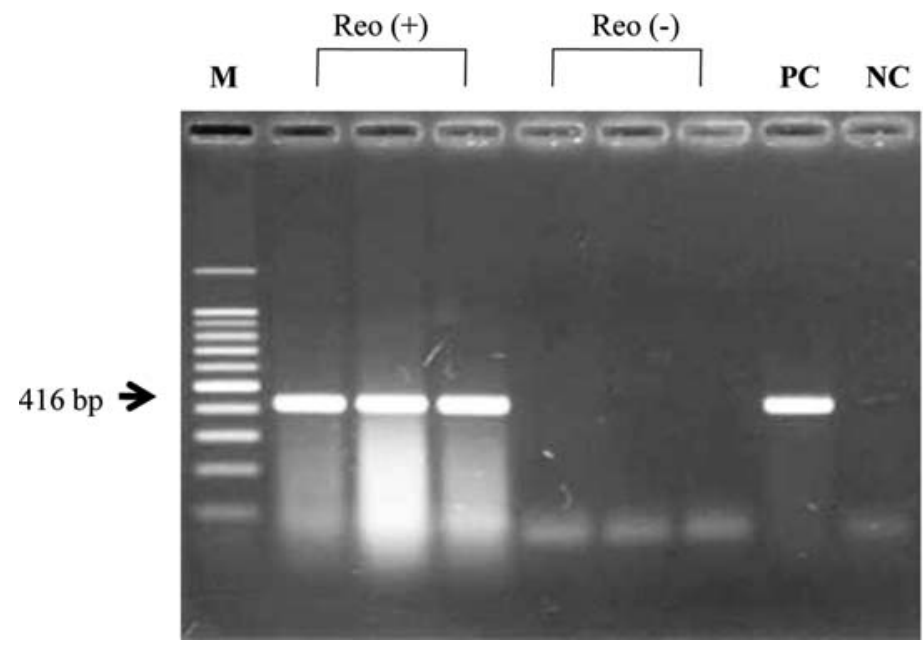

M: marker

PC: positive control

NC: negative control

$(+)$ : Reovirus treatment

$(-)$ : Reovirus control

Figure 5. RT-PCR analysis of metastatic nodules of MKN45p cells in the peritoneal cavity. The reovirus L1 gene segment region was detected in all metastatic nodules of the reovirus treatment group.

Oncolytic efficacy of reovirus treatment in vivo. Images of representative mice on day 18 after inoculation of MKN45p cells are shown in Fig. 4A. On day 18 after inoculation, the mean volume of ascites in the reovirus treatment group $(n=10)$ was less than that in the control group $(n=10)$ $(0.14 \mathrm{ml}$ vs $3.86 \mathrm{ml} ; \mathrm{P}<0.05)$ (Fig. 4B). The mean total number of disseminated MKN45p cell tumors in the mesenterium of mice in the reovirus treatment group was also less than that in the control group (11.9 vs $65.2 ; \mathrm{P}<0.05)$ (Fig. 4C). The total weight of the peritoneal tumors in the mesenterium of each mouse in the reovirus treatment group was signifi- cantly less than that in the control group (113 mg vs $546 \mathrm{mg}$; $\mathrm{P}<0.05$ ) (Fig. 4D). Amplified reovirus genomic segments from the reovirus treatment and reovirus control groups are shown in Fig. 5. The reovirus L1 gene segment region was detected in all metastatic nodules in the reovirus treatment group.

Post-treatment histology in the mouse model. H\&E staing showed viral-induced CPEs and necrosis as indicated by neutrophil infiltration in the MKN45p cell tumors treated by reovirus (Fig. 6). 

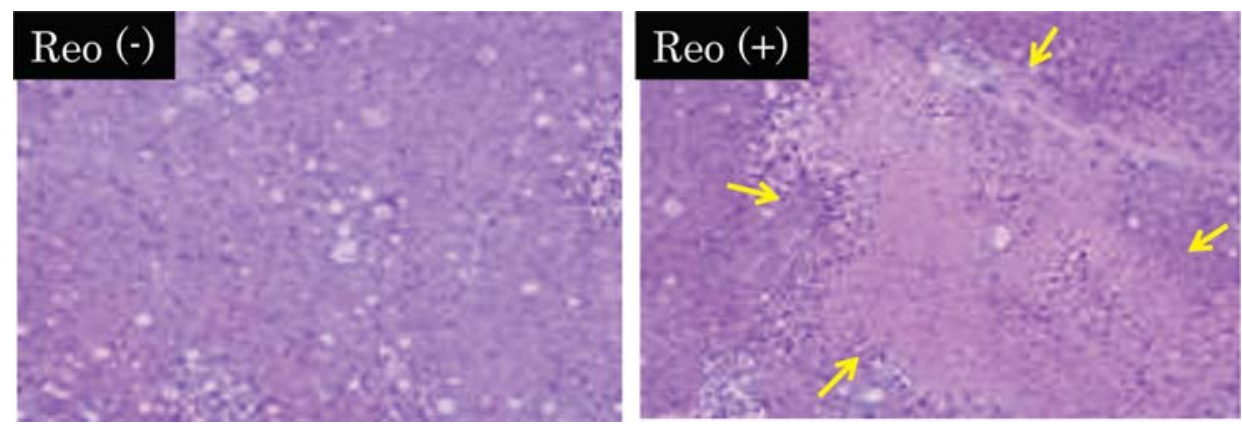

Figure 6. Post-treatment histology in the mouse model. H\&E staining shows a necrotic area with neutrophil infiltration within the reovirus-treated peritoneal tumors of MKN45p cells. Original magnification, $\mathrm{x} 100$.

\section{Discussion}

To our knowledge, this is the first study to provide evidence of the efficacy of reovirus as a novel therapeutic agent against gastric cancer in the preclinical setting. Reovirus is a novel oncolytic agent against cancer cells that is based on targeting of the activated Ras signaling pathway via direct Ras mutation or the independent pathways downstream of Ras $(17,18)$. Roughly $50 \%$ of all cancers have an activated Ras signaling pathway because of activating mutations in the Ras gene itself and in genes upstream or downstream of Ras (8). Although overexpression of EGFR in gastric cancer has been well documented (19), the status of Ras mutations in the human gastric cancer cell lines used in this study is unknown at present. The present study shows that the activity of Ras was elevated in all gastric cancer cells.

In contrast, there are studies showing no significant association between ReoT3D permissibility and the presence of Ras-activating gene mutations or activated Ras in human NSCLC cells (20). The lack of this association has also been reported in human colon cancers (21). It is possible that in addition to the activation status of Ras-associated pathways $(8,22)$, there are other molecular determinants of ReoT3D sensitivity, such as the cell surface density of putative ReoT3D receptors/coreceptors (23-25) and intracellular virion uncoating processes $(26,27)$, all of which can affect ReoT3D infection efficiency. In regard to gastric cancer cells, Cho et al recently reported a mechanism in which the reovirus acts by downregulating Akt activation and induction of apoptosis in SNU-216 gastric cancer cells (28). Thus, the susceptibility of human gastric cancer cell lines to reovirus is attributable not only to activating mutations in Ras itself but can also be a result of activation or overexpression of regulatory elements in Ras signaling pathways or others mechanisms.

In the present study, to treat peritoneal metastasis of gastric cancer, the route of systemic delivery is important for regression of these tumors (29-31). Intravenous injection or intraperitoneal delivery may allow reovirus to reach inaccessible tumors and treat undetectable micrometastases. However, these methods might also affect the effectiveness and toxicity of the therapy. Oncolytic viruses including genetically engineered vaccinia, herpes simplex virus, adenovirus and measles and non-engineered viruses such as Newcastle disease virus and reovirus have been studied in clinical trials (32-36). Most of these trials have shown systemic efficacy via intratumoral injection or intravenous administration of viruses. A phase I intravenous dose escalation trial of reovirus was reported in 29 patients with cutaneous metastases from systemic cancers (36). Antitumoral efficacy was suggested in 5 patients with stable disease for 4-6 months, and a $>50 \%$ decrease in blood tumor marker and/or tumor necrosis was also observed. Therefore, intravenous administration of reovirus is considered to be effective in the treatment of refractory cancer patients. In the clinical setting, repeated intraperitoneal reovirus treatment may be beneficial because such administration of virus in patients with peritonitis carcinomatosa is more feasible than is intratumoral administration against visceral cancers. Because intraperitoneal reovirus therapy has not yet been clinically reported, further clinical trials are eagerly anticipated in the near future.

Recently, preliminary findings from ongoing phase I clinical trials evaluating the safety of a reovirus type 3-taxane combination in patients with chemotherapy-refractory advanced tumors have shown objective anticancer response in some patients without serious side-effects $(37,38)$. Use of this reovirus in combination with anti-cancer drugs may provide hoped-for treatment of gastric cancer with peritoneal dissemination in the future.

In conclusions, peritoneal metastasis of gastric cancer is a critical problem because of the limited number of available therapeutic modalities. The present study in a mouse model indicates that intraperitoneal administration of reovirus could potentially be useful as a new treatment modality against gastric cancer with peritoneal dissemination.

\section{References}

1. Murray CJ and Lopez AD: Alternative projections of mortality and disability by cause 1990-2020: Global burden of disease study. Lancet 349: 1498-1504, 1997.

2. Japanese Gastric Cancer Association: Gastric cancer treatment guidelines for doctors' reference (in Japanese). Kanehara, Tokyo, 2004

3. Kitayama J, Ishigami H, Kaisaki S, Hidemura A, Kato M, Otani K, Kamei T, Soma D, Miyato H, Yamashita $\mathrm{H}$ and Nagawa $\mathrm{H}$ : Weekly intravenous and intraperitoneal paclitaxel combined with S-1 for malignant ascites due to advanced gastric cancer. Oncology 78: 40-46, 2010

4. Imazawa M, Kojima T, Boku N, Onozawa Y, Hironaka S, Fukutomi A, Yasui H, Yamazaki K and Taku K: Efficacy of sequential methotrexate and 5-fluorouracil (MTX/5FU) in improving oral intake in patients with advanced gastric cancer with severe peritoneal dissemination. Gastric Cancer 12: 153-157, 2009. 
5. Okabe H, Ueda S, Obama K, Hosogi H and Sakai Y: Induction chemotherapy with S-1 plus cisplatin followed by surgery for treatment of gastric cancer with peritoneal dissemination. Ann Surg Oncol 16: 3227-3236, 2009.

6. Mochiki E, Shioya M, Sakurai H, Andoh H, Ohno T, Aihara R, Asao $\mathrm{T}$ and Kuwano $\mathrm{H}$ : Feasibility study of postoperative intraperitoneal hyperthermochemotherapy by radiofrequency capacitive heating system for advanced gastric cancer with peritoneal seeding. Int J Hyperthermia 23: 493-500, 2007.

7. Yonemura Y, Kawamura T, Bandou E, Takahashi S, Sawa T and Matsuki N: Treatment of peritoneal dissemination from gastric cancer by peritonectomy and chemohyperthermic peritoneal perfusion. Br J Surg 92: 370-375, 2005.

8. Strong JE, Coffey MC, Tang D, Sabinin P and Lee PW: The molecular basis of viral oncolysis: usurpation of the Ras signaling pathway by reovirus. EMBO J 17: 3351-3362, 1998.

9. Etoh T, Himeno Y, Matsumoto T, Aramaki M, Kawano K, Nishizono A and Kitano S: Oncolytic viral therapy for human pancreatic cancer cells by reovirus. Clin Cancer Res 9: 1218-1223, 2003.

10. Himeno Y, Etoh T, Matsumoto T, Ohta M, Nishizono A and Kitano S: Efficacy of oncolytic reovirus against liver metastasis from pancreatic cancer in immunocompetent models. Int J Oncol 27: 901-906, 2005.

11. Hirano S, Etoh T, Okunaga R, Shibata K, Ohta M, Nishizono A and Kitano S: Reovirus inhibits the peritoneal dissemination of pancreatic cancer cells in an immunocompetent animal model. Oncol Rep 21: 1381-1384, 2009.

12. Forsyth P, Roldán G, George D, Wallace C, Palmer CA, Morris D, Cairncross G, Matthews MV, Markert J, Gillespie Y, Coffey M, Thompson B and Hamilton M: A phase I trial of intratumoral administration of reovirus in patients with histologically confirmed recurrent malignant gliomas. Mol Ther 16: 627-632, 2008.

13. Hirasawa K, Nishikawa SG, Norman KL, Alain T, Kossakowska A and Lee PW: Oncolytic reovirus against ovarian and colon cancer. Cancer Res 62: 1696-1701, 2002.

14. Hata Y, Etoh T, Inomata M, Shiraishi N, Nishizono A and Kitano $\mathrm{S}$ : Efficacy of oncolytic reovirus against human breast cancer cells. Oncol Rep 19: 1395-1398, 2008.

15. Smith RE, Zweerink HJ and Joklik WK: Polypeptide components of virions, top component and cores of reovirus type 3 . Virology 39: 791-810, 1969.

16. Lee PW, Hayes EC and Joflik WK: Protein sigma 1 is the reovirus cell attachment protein. Virology 108: 156-163, 1981.

17. Wilcox ME, Yang W, Senger D, Rewcastle NB, Morris DG, Brasher PM, Shi ZQ, Johnston RN, Nishikawa S, Lee PW and Forsyth PA: Reovirus as an oncolytic agent against experimental human malignant gliomas. J Natl Cancer Inst 93: 903-912, 2001.

18. Alain T, Hirasawa K, Pon KJ, et al: Reovirus therapy of lymphoid malignancies. Blood 100: 4146-4153, 2002

19. Kim MA, Lee HS, Lee HE, Jeon YK, Yang HK and Kim WH: EGFR in gastric carcinomas: prognostic significance of protein overexpression and high gene copy number. Histopathology 52 : 738-746, 2008.

20. Sei S, Mussio JK, Yang QE, Nagashima K, Parchment RE, Coffey MC, Shoemaker RH and Tomaszewski JE: Synergistic antitumor activity of oncolytic reovirus and chemotherapeutic agents in non-small cell lung cancer cells. Mol Cancer 14: 47, 2009.

21. van Houdt WJ, Smakman N, van den Wollenberg DJ, Emmink BL, Veenendaal LM, van Diest PJ, Hoeben RC, Borel Rinkes IH and Kranenburg O: Transient infection of freshly isolated human colorectal tumor cells by reovirus T3D intermediate subviral particles. Cancer Gene Ther 15: 284-292, 2008.

22. Norman KL, Hirasawa K, Yang AD, Shields MA and Lee PW: Reovirus oncolysis: the Ras/RalGEF/p38 pathway dictates host cell permissiveness to reovirus infection. Proc Natl Acad Sci USA 101: 11099-11104, 2004.

23. Barton ES, Forrest JC, Connolly JL, Chappell JD, Liu Y, Schnell FJ, Nusrat A, Parkos CA and Dermody TS: Junction adhesion molecule is a receptor for reovirus. Cell 104: 441-451, 2001 .
24. Strong JE and Lee PW: The V-erbB oncogene confers enhanced cellular susceptibility to reovirus infection. J Virol 70: 612-616, 1996.

25. Chappell JD, Gunn VL, Wetzel JD, Baer GS and Dermody TS: Mutations in type 3 reovirus that determine binding to sialic acid are contained in the fibrous tail domain of viral attachment protein sigma1. J Virol 71: 1834-1841, 1997.

26. Golden JW, Linke J, Schmechel S, Thoemke K and Schiff LA: Addition of exogenous protease facilitates reovirus infection in many restrictive cells. J Virol 76: 7430-7443, 2002.

27. Alain T, Kim TS, Lun X, Liacini A, Schiff LA, Senger DL and Forsyth PA: Proteolytic disassembly is a critical determinant for reovirus oncolysis. Mol Ther 15: 1512-1521, 2007

28. Cho IR, Koh SS, Min HJ, Park EH, Srisuttee R, Jhun BH, Kang CD, Kim M, Johnston RN and Chung YH: Reovirus infection induces apoptosis of TRAIL-resistant gastric cancer cells by down-regulation of Akt activation. Int J Oncol 36: 1023-1030, 2010

29. Link CJ, Moorman DW, Ackerman M, Levy JP and Seregina T: Murine retroviral vector producer cells survival and toxicity in the peritoneal cavity of dogs. In Vivo 14: 635-641, 2000.

30. Gordon EM, Chen ZH, Liu L, Whitley M, Wei D, Groshen S, Hinton DR, Anderson WF, Beart RW Jr and Hall FL: Systemic administration of a matrix-targeted retroviral vector is efficacious for cancer gene therapy in mice. Hum Gene Ther 12: 193-204, 2001.

31. Tam P, Monck M, Lee D, Ludkovski O, Leng EC, Clow K, Stark H, Scherrer P, Graham RW and Cullis PR: Stabilized plasmid-lipid particles for systemic gene therapy. Gene Ther 7: 1867-1874, 2000.

32. Dewey RA, Morrissey G, Cowsill CM, Stone D, Bolognani F, Dodd NJ, Southgate TD, Klatzmann D, Lassmann H, Castro MG and Löwenstein PR: Chronic brain inflammation and persistent herpes simplex virus 1 thymidine kinase expression in survivors of syngeneic glioma treated by adenovirus-mediated gene therapy: implications for clinical trials. Nat Med 5: 1256-1263, 1999.

33. Mastrangelo MJ, Maguire HC Jr, Eisenlohr LC, Laughlin CE, Monken CE, McCue PA, Kovatich AJ and Lattime EC: Intratumoral recombinant GM-CSF-encoding virus as gene therapy in patients with cutaneous melanoma. Cancer Gene Ther 6: 409-422, 1999.

34. Pecora AL, Rizvi N, Cohen GI, Meropol NJ, Sterman D, Marshall JL, Goldberg S, Gross P, O'Neil JD, Groene WS, Roberts MS, Rabin H, Bamat MK and Lorence RM: Phase I trial of intravenous administration of PV701, an oncolytic virus, in patients with advanced solid cancers. J Clin Oncol 20: 2251-2266, 2002.

35. Nemunaitis J, Cunningham C, Buchanan A, Blackburn A, Edelman G, Maples P, Netto G, Tong A, Randlev B, Olson S and Kirn D: Intravenous infusion of a replication-selective adenovirus (ONYX-015) in cancer patients: safety, feasibility and biological activity. Gene Ther 8: 746-759, 2001.

36. Morris D, Forsyth PA, Patherson AH, et al: A phase I clinical trial evaluating intralesional Reolysin (reovirus) in histologically confirmed malignancies. Proc Am Soc Clin Oncol Annu Meet 21: $92: 24,2002$.

37. Comins C, Spicer J, Protheroe A, Mukherji D, Coffey M, Thompson $\mathrm{B}$, Harrington $\mathrm{K}$ and Pandha $\mathrm{H}$ : A phase I study to evaluate systemic wild-type reovirus (Reolysin) in combination with docetaxel in patients with advanced malignancies. In: International Society for Biological Therapy of Cancer 23rd Annual Meeting Abstracts San Diego, CA. J Immunother 31: 951, 2008.

38. Karapanagiotou E, Pandha H, Hall G, Chester J, Melcher A, De Bono J, Gore M, Nutting C and Harrington K: Phase I trial of oncolytic reovirus (Reolysin) in combination with carboplatin/ paclitaxel in patients with advanced solid cancers. In: International Society for Biological Therapy of Cancer 23rd Annual Meeting Abstracts San Diego, CA. J Immunother 31: 952,2008 . 